\title{
HINDFOOT DISABILITY AFTER A TIBIAL SHAFT FRACTURE TREATED BY INTERNAL FIXATION
}

\author{
W. F. MERRIAM, K. M. PORTER
}

From the Coventry and Warwickshire Hospital, Coventry

\begin{abstract}
One hundred patients who had sustained a fracture of the tibial shaft and had been treated by internal fixation were reviewed to obtain information on residual ankle and subtalar disability. This study reinforces the belief that early mobilisation of patients with tibial shaft fractures does help to preserve subtalar movement.
\end{abstract}

Debate on the management of tibial fractures, between supporters of operative and non-operative treatment, has been passionate. One of the often repeated assertions of the operative school has been that internal fixation and early movement will preserve joint mobility whereas prolonged conservative treatment will induce disabling "fracture disease". This controversy has been largely based on assertion and the present study examines this question objectively.

Ellis (1958) showed that stiffness was directly related to the severity of a tibial fracture but could not say whether immobilisation per se caused stiffness. He found that six per cent of 343 patients with healed tibial shaft fractures which had been treated conservatively had "limitation of ankle or foot movement, or both", but gave no further details about how this was defined or measured. He felt that stiffness was caused by direct injury to the tissues or associated vascular damage.

In a series of 241 conservatively treated patients, Nicoll (1964) found 25 per cent to have significant residual stiffness in one or more joints (defined as 25 to 50 per cent of flexion and extension of the ankle or inversion and eversion of the foot), but thought this was not functionally significant. Eighteen patients (seven per cent) had severe stiffness (greater than 50 per cent loss of movement). However, he felt that residual stiffness was not a serious hazard of conservative treatment and said there was no proof that internal fixation, even with immediate movement, averted stiffness, although he thought it might lessen it.

However, Blockey (1956) found that 66 per cent of 30 plated tibiae treated with early mobilisation had no

W. F. Merriam, FRCS, Senior Registrar in Orthopaedics Coventry and Warwickshire Hospital, Stoney Stanton Road, Coventry CVI 4FH, England.

K. M. Porter, FRCS, Senior Registrar

Royal Orthopaedic Hospital, Woodlands, Northfields, Birmingham B31 2AP, England.

Requests for reprints should be sent to Mr W. F. Merriam.

(C) 1983 British Editorial Society of Bone and Joint Surgery $0301-620 X / 83 / 3072-0326 \$ 2.00$ joint stiffness; Muller (1963) claimed similar results, as did Burns and Young (1944). Burwell (1971) reported a series of 181 internally fixed tibial shaft fractures, noting that 19.5 per cent had "marked stiffness of the ankle and foot". He felt operation was actually beneficial, preventing stiffness by releasing the haematoma distending the leg and relieving "the tissue tension under tight fascial structures" referred to by Nicoll.

McMaster's study (1976) of hindfoot disability after conservatively treated tibial shaft fractures is noteworthy because, first, he had an objective method of joint recording and, secondly, he confirmed Ellis' finding that severity of the fracture is related to joint stiffness. In McMaster's series of cases 72 per cent had some limitation of subtalar movement; he did not examine ankle movements. Factors associated with this limitation were the age of patient, the site of the fracture, the duration of immobilisation, the severity of trauma, wound infection and non-union, and oedema of the ankle after removal of the cast.

The object of the present study of 100 patients in whom tibial fractures had been treated by internal fixation was to investigate the effects of this treatment on ankle and hindfoot mobility and to assess late symptoms and signs attributable to ankle and hindfoot disability. McMaster's report enables us to compare our findings with those of a conservatively treated similar group of patients.

\section{PATIENTS AND METHODS}

One hundred consecutive patients treated at the Coventry and Warwickshire Hospital between the years 1974 and 1979 (mean followup 43.6 months) were recalled and seen by the authors. All patients had sustained a fracture of one tibial shaft and had been treated by internal fixation (AO DC plates). Details of the patients and their fractures are given in Table I. Most patients had had their fractures plated on the day of admission. The leg had been rested on a Braun's frame until the wound was healed and the sutures removed. Active movements had been encouraged on the day after operation, but no weight-bearing had been allowed until the surgeon was convinced that union had occurred.

Fractures were divided into two grades of severity. A fracture of major severity was one where there was severe comminution with or without an open wound; in one of minor severity there was minimal 
Table I. Details of tibial fractures in 100 patients

\begin{tabular}{|lll|}
\hline Mean age & & 32.4 years \\
Sex & Female & 15 \\
Severity of injury & Male & 85 \\
& Minor & 82 \\
Site of tibial fracture & Major & 18 \\
& Uppermost third & 6 \\
& Middle third & 46 \\
& Lowermost third & 48 \\
\hline
\end{tabular}

comminution or none, and compounding if present was small and occurred from within. McMaster used this classification modified from Ellis' earlier description.

At follow-up, ankle and subtalar movement were determined by the use of an aluminium pointer which was attached via a moulded plaster-of-Paris support and Velcro straps to each heel in turn. The patient was placed in the prone position with the knee flexed, and the pointer was attached and set against a board from which the range of ankle and subtalar movements could be read off. The range at the ankle was found by taking the difference between full dorsiflexion and ful plantar flexion, and subtalar range by taking the difference between ful inversion and full eversion. Subtalar and ankle movements were recorded as a fraction of that of the opposite normal limb. Mild restriction of movement preserved more than two-thirds of the normal range; moderate restriction allowed a range of one-third to two-thirds of the normal; and severe restriction produced a range of less than onethird of the normal.

Table II. Limitation of subtalar movement

\begin{tabular}{|lllll|}
\hline & Severe & Moderate & Mild & Normal \\
\hline Number of patients & 6 & 18 & 26 & 50 \\
Severity of injury & & & & \\
Minor & 4 & 15 & 18 & 45 \\
Major & 2 & 3 & 8 & 5 \\
Site of tibial fracture & & & & \\
Uppermost third & 0 & 2 & 0 & 3 \\
Middle third & 4 & 7 & 14 & 21 \\
Lowermost third & 2 & 9 & 12 & 26 \\
\hline
\end{tabular}

Table III. Limitation of ankle movement

\begin{tabular}{|lllll|}
\hline & Severe & Moderate & Mild & Normal \\
\hline Number of patients & 2 & 12 & 46 & 40 \\
Severity of injury & & & & \\
Minor & 1 & 9 & 39 & 33 \\
Major & 1 & 3 & 7 & 7 \\
Site of tibial fracture & & & & \\
Uppermost third & 0 & 1 & 2 & 2 \\
Middle third & 2 & 4 & 22 & 18 \\
Lowermost third & 0 & 7 & 22 & 20 \\
\hline
\end{tabular}

VOL. 65-B, No. 3, MAY 1983
Thickening of the ankle was measured with a pair of calipers placed two centimetres below the lateral malleolus and spanning the heel. Thickening of more than half a centimetre on the injured side was taken as significant.

\section{RESULTS}

We found that 50 patients had some degree of stiffness in the subtalar joint but the remaining 50 patients had a range of movement identical to that in the unaffected limb (Table II). Ankle movement appeared to be more severely affected, with 60 patients having some degree of stiffness (Table III). We did not find that a major injury was associated with increased stiffness of subtalar or ankle joints; neither did we find that the site of the tibial fracture was associated with any particular degree of stiffness of these joints.

The duration of non-weight-bearing was not directly related to an increasing degree of stiffness, neither was there a greater incidence of ankle swelling in the group with severe restriction of movement. We found ankle swelling in only nine patients.

Table IV. Residual symptoms

\begin{tabular}{|ll|}
\hline Symptoms & Number of patients \\
\hline Pain & 31 \\
Stiffness & 13 \\
$\begin{array}{l}\text { Difficulty walking over } \\
\text { uneven ground }\end{array}$ & 14 \\
$\begin{array}{l}\text { Difficulty walking over } \\
\text { even ground }\end{array}$ & 5 \\
$\begin{array}{l}\text { Swelling } \\
\begin{array}{l}\text { Interference with work or } \\
\text { recreation }\end{array}\end{array}$ & 16 \\
\hline
\end{tabular}

Sixteen patients had symptoms sufficiently severe to interfere with work or recreational activity (Table IV). Thirty-one patients complained of some degree of pain and 46 patients had residual symptoms.

\section{DISCUSSION}

The results of our study were compared with McMaster's (1976) conservatively treated series of tibial fractures. While McMaster's study was carried out in a different hospital and region and there may be inter-observer errors, there is, nevertheless, striking similarity in the position and type of the fractures which gives the comparison considerable validity. In addition, mean follow-up in our series was $\mathbf{4 3 . 6}$ months compared to $\mathbf{4 0}$ months in McMaster's series.

Whereas 50 per cent of our operated patients had some degree of subtalar stiffness, 72 per cent of McMaster's series showed stiffness. Only 24 per cent of our patients fell into the groups with severe and moderate limitation of subtalar movement compared to 45 per cent 
in McMaster's series. Whereas our whole cohort were of mean age 32.4 years in comparison with 36.3 years for McMaster's patients, those of our patients with severe or moderate limitation had a mean age of 35.1 years compared with a mean age of $\mathbf{4 4 . 8}$ years for these groups in McMaster's series. Hence, it is the older patient who appears to be more susceptible to stiffness when treated conservatively. During this crucial decade activity declines; superimposed immobilisation probably makes recovery of full subtalar movement more difficult than when active movements are encouraged on the day after operation. Our conclusion would be that whereas surgical management of the fracture tends to allow freer movement in the joint at all ages, this seems to be a particularly important advantage in the middle-aged and older patients.

McMaster found a clear association between severity of injury and stiffness (as did Ellis), but this series of operatively treated fractures does not substantiate this. Only 28 per cent of our major injuries fell into the groups with severe and moderate limitation of subtalar movement whereas 66 per cent of McMaster's major injuries fell into these two groups.

McMaster found that 62 per cent of 50 fractures in the lowermost third of the tibia fell into the groups with severe and moderate limitation of subtalar movement, whereas only 14 per cent of our 49 similar fractures fell into these two groups.

Overall 46 per cent of patients in our series had residual symptoms compared to 43 per cent in those of McMaster's series. McMaster found 12 per cent to have troublesome symptoms which were sufficiently severe to interfere with work and recreational activity compared with 16 per cent in our series, and this small but significantly adverse reflection on surgically treated cases requires further explanation. It might have been expected that fewer operated patients would have troublesome symptoms in the light of the enhanced hindfoot function they showed in our series. Our higher rate of troublesome symptoms may be explained by a combination of factors: the patients in our series are younger, and may, therefore, demand better hindfoot function; many of our patients still had plates in situ and we gained the impression that symptoms sometimes improved after removal of the plate; our patients received earlier and probably more intensive physiotherapy and were, therefore, more likely to be aware of their hindfoot function. McMaster found 56 per cent to have long-term swelling of the ankle compared with nine per cent in our series.

McMaster carried out radiography of the subtalar joints on all his patients but found no evidence of damage to joint surfaces. He concluded that limitation of hindfoot movement was caused by changes in intra-articular or extra-articular soft-tissue structures rather than damage to the joint itself. In our series, where hindfoot disability is less marked, it would seem reasonable to conclude that limitation of movement is due to soft-tissue structures. McMaster felt that disability was caused by prolonged oedema giving rise to a fibroblastic reaction in the soft tissues of the submalleolar region, so restricting hindfoot movement. The very low incidence of ankle swelling in our patients may help to explain the marked reduction in subtalar disability. A heavy plaster cast would certainly encourage swelling, first by virtue of its weight and, secondly, because immobility appears to encourage swelling.

In conclusion, we agree with Ellis (1958) that stiffness of the joint after tibial fracture is not related to the site of the fracture in the tibia. From this review, operative treatment appears to reduce the incidence and severity of residual ankle and subtalar stiffness, but does not abolish it. Further work and more objective evidence is needed to support or deny the assertion that surgery and early movement will preserve joint function.

The authors would like to thank Mr M. H. M. Harrison for his help and encouragement during preparation of this paper. We also wish to thank Mr P. E. H. Wilson, Mr R. James, Mr J. Clegg and Mr M. J. Aldridge for permission to publish details of their patients. Finally, we wish to thank Mrs R. Charvill for typing the manuscript.

\section{REFERENCES}

Blockey NJ. The value of rigid fixation in the treatment of fractures of the adult tibial shaft. J Bone Joint Surg [Br] 1956;38-B:518-27.

Burns BH, Young RH. Early movement in the treatment of closed fractures. Lancet 1944;i:723-5.

Burwell HN. Plate fixation of tibial shaft fractures: a survey of 181 injuries. $J$ Bone Joint Surg [Br] 1971;53-B:258-71.

Ellis H. Disabilities after tibial shaft fractures: with special reference to Volkmann's ischaemic contracture. J Bone Joint Surg [Br] 1958; 40-B: $190-7$.

McMaster M. Disability of the hindfoot after fracture of the tibial shaft. J Bone Joint Surg [Br] 1976;58-B:90-3.

Muller ME. Internal fixation for fresh fractures and for non-union. Proc $R$ Soc Med 1963;56:455-60.

Nicoll EA. Fractures of the tibial shaft : a survey of 705 cases. J Bone Joint Surg [Br] 1964;46-B:373-87. 